\section{A transformation program for normalizing data}

\author{
JOHN E. LANGHORNE, JR. and JAN LONEY \\ Department of Psychiatry, University of Iowa \\ Iowa City, Iowa 52242 \\ and \\ MICHAEL HACKER \\ Rockefeller University, New York, New York 10021
}

A central concern in the use of parametric statistics is the extent to which deviations from the basic assumptions erode the power of a statistical test. Numerous empirical studies have been performed (Boneau, 1960; Donaldson, 1968; Lindquist, 1953; Norris \& Hjelm, 1961) that demonstrate the substantial robustness of most univariate tests. It is hopeful to assume that univariate robustness will generalize to the multivariate case, but at this time empirical proof is in short supply (Davidson, 1972; Olson, 1976). As a result of this situation, it behooves the multivariate investigator to be somewhat more sensitive to scaling, normality, and homogeneity of variance considerations than his univariate brethren.

Winer (1971), in a discussion of measurement and transformation, suggests three basic monotonic transformations: square root, arcsin, and logarithmic. All of these are effective in stabilizing variances. However, these transformations, with the exception of the logarithmic and square root in the case of positive skewness, are not notably effective in normalizing distributions.

Thurstone (1959) suggested a monotonic transformation to create "normal" scores of ranked data. The transformed value is the difference in the height of the normal curve at the upper $\left[f\left(X_{k}\right)\right]$ and the lower [ $\left.f\left(X_{k-1}\right)\right]$ bounds of the corresponding interval, divided by the area $\left(\mathrm{P}_{\mathrm{k}}\right)$ bounded by the curve within that interval: $\quad Z_{T}=\left[f\left(X_{k-1}\right)-f\left(X_{k}\right)\right] / P_{k}$, where $Z_{T}$ is the transformed value. It can be shown that this transformation sets the means to zero, the variances are homogenized with the upper limit approximately equal to one, and the maximum possible normalization of the distribution occurs under the scale limitations. Thus some normalization occurs with distributions of any shape, and this suggests greater generality than either the logarithmic or square-root transformations.

This program accepts input data, transforms them according to the preceding formula, and outputs the new vaiues.

Input. The input consists of (1) raw data, (2) format card, and (3) program parameter cards, including (a) the number of cases, (b) the total number of variables, (c) the number of variables to be transformed, (d) the maximum number of missing values for any variable, (e) a flag indicating whether missing values should lead to deletion of the entire case or just the particular missing value for the case at hand, (f) the value to be substituted for all missing values, and $(\mathrm{g})$ an estimate of the sum of the number of different values for each variable to be transformed.

Output. As the program is currently written, the transformed values are output as punched cards in the prespecified format.

Computer and Language. The program is written in $\mathrm{PL} / 1$ and currently is operating on an IBM 360/65 under the OS/MVT-HASP system.

Portability. The program should be operable on systems with $\mathrm{PL} / 1$ by modifying the job control language appropriate to the facility. The source listing includes sample input and output to assist in this process.

Availability. The source listing and documentation may be obtained by writing John E. Langhorne, Jr., at the Iowa Mental Health Authority, University of Iowa, Oakdale Campus, Oakdale, Iowa 52319.

\section{REFERENCES}

Boneau, C. A. The effects of violations of assumptions underlying the $t$ test. Psychological Bulletin, 1960, 57, 49-64.

Davidson, M. L. Univariate versus multivariate tests in repeated measures experiments. Psychological Bulletin, 1972, 77, 446-452.

Donaldson, T. S. Robustness of the F-test to errors of both kinds and the correlation between numerator and denominator of the F-ratio. American Statistical Association Journal, $1968,63,660-676$.

LINDQuist, E. F. Design and analysis of experiments in psychology and education. Boston: Houghton-Mifflin, 1953.

Norris, R. C., \& HJelm, H. F. Non-normality and product moment correlation. Journal of Experimental Education, 1961, 29, 261-270.

Orson, C. L. On choosing a test statistic in multivariate analysis of variance. Psychological Bulletin, 1976, 83, 579-586.

ThuRstone, L. L. The measurement of values. Chicago: University of Chicago Press, 1959.

WINER, B. J. Statistical principles in experimental design (2nd ed.). San Francisco: McGraw-Hill, 1971.

(Accepted for publication July 19, 1978.) 